\title{
Reliability of the MMSE Administered In-Person and by Telehealth
}

\author{
Wendaline McEachern, Andrew Kirk, Debra G. Morgan, Margaret Crossley, \\ Carol Henry
}

\begin{abstract}
Background: Recent advances in telehealth have improved access to health care for those in rural areas. It is important that examinations conducted via telehealth are comparable to in-person testing. A rural and remote memory clinic in Saskatoon provided an opportunity to compare scores on the Mini-Mental State Examination (MMSE) administered in-person and via telehealth. Methods: After an initial one day assessment in Saskatoon, patients were seen in follow-up at 6 and 12 weeks. Individual patients were randomly assigned to either in-person follow-up assessment in Saskatoon or telehealth assessment in their home community. Patients who initially received in-person assessments were seen by telehealth for their next follow-up visit and vice-versa. The same neurologist administered MMSEs at all visits. The first 71 patients with both 6 and 12 week follow-up assessments were included in this study. The scores of in-person and telehealth MMSE administrations were compared using the methods of Bland and Altman as well as a paired ttest. Results: MMSE scores did not differ significantly between telehealth (22.34 +/- 6.35) and in-person $(22.70+/-6.51)$ assessments. Conclusion: Telehealth provides an acceptable means of assessing mental status of patients in remote areas.
\end{abstract}

RÉSUMÉ: Fiabilité du MMSE administré en personne et par télésanté. Contexte : Les progrès récents de la télésanté ont amélioré l'accès aux soins de santé par les habitants des régions rurales. Il est important que les examens effectués via télésanté soient comparables à ceux effectués en personne. Une clinique de la mémoire dans une région rurale éloignée à Saskatoon a fourni l'occasion de comparer les scores du Mini-Mental State Examination (MMSE) administré en personne et via télésanté. Méthodes : Suite à une évaluation initiale d'une journée à Saskatoon, les patients ont été réévalués 6 et 12 semaines plus tard. Les patients ont été assignés au hasard soit à une évaluation de suivi en personne à Saskatoon ou à une évaluation via télésanté dans leur lieu de résidence. Les patients qui ont reçu initialement des évaluations en personne ont été vus par télésanté à leur visite de suivi subséquente et vice-versa. Le même neurologue administrait le MMSE à toutes les visites. Les premiers 71 patients qui ont eu une évaluation de suivi après 6 et 12 semaines ont été inclus dans cette étude. Les scores au MMSE obtenus en personne et via télésanté ont été comparés au moyen des méthodes de Bland et Altman ainsi que par test de t apparié. Résultats : Les scores du MMSE n'étaient pas significativement différents entre les évaluations via télésanté $(22,34 \pm 6,35)$ et en personne $(22,70 \pm 6,51)$. Conclusion : La télésanté est un moyen acceptable d'évaluer l'état mental de patients résidant dans des régions éloignées.

Can. J. Neurol. Sci. 2008; 35:643-646

In recent years, the burgeoning field of telemedicine has improved access to health care for those in rural and remote areas. ${ }^{1}$ Given the aging demographic in these locations, ${ }^{2}$ there is a growing need to assess and treat patients with dementia. ${ }^{3}$ Advances in telehealth services hinge on improvements in videoconferencing technology and on the reliability of clinical data such as mental status assessment compared to that obtained from in-person assessments. ${ }^{4}$ It is possible that sensory impairments or unfamiliarity with videoconferencing technology could hinder performance on mental status tests by elderly persons with dementia. On the other hand, greater convenience and reduced travel time ${ }^{5}$ might lead to better performance.

Previous studies have suggested that discrepancies in mental status screening exist between telehealth and in-person modalities, ${ }^{6-8}$ while others have suggested that the scores are comparable overall but that some individuals perform more poorly when assessed via telehealth. ${ }^{9}$ Prior studies in this area have included small sample sizes and have not necessarily been in clinical settings. ${ }^{6-9}$ Correlations have sometimes been used instead of measures of equivalency.

From the Division of Neurology (AK), Institute of Agriculture Rural \& Environmenta Health (DGM), Department of Medicine, Department of Psychology (MC), Aging Research \& Memory Clinic, University of Saskatchewan; Telehealth Department, Saskatoon Health Region (CH), Saskatoon; College of Medicine (WM), University of Saskatchewan, Saskatoon, Saskatchewan, Canada.

Received February 5, 2008. Final Revisions Submitted May 12, 2008. Correspondence to: Andrew Kirk, Division of Neurology, Royal University Hospital, 103 Hospital Drive, Saskatoon, Saskatchewan, S7N 0W8, Canada. 
Within the past few years, the need to serve patients with dementia prompted the establishment of a Rural and Remote Memory Clinic based in Saskatoon. ${ }^{10,11}$ The Memory Clinic provided a useful framework for examining the utility of the Mini-Mental State Examination (MMSE) ${ }^{12}$ in a large pool of patients, both in-person and via telehealth, at varying intervals over a prolonged time. One of the goals of this study was to determine whether MMSE scores are comparable when administered over telehealth vs. in-person.

\section{Methods}

Data collection began in March 2004 in the context of the Rural and Remote Memory Clinic. Patients were referred by their family physicians. Assessment began with a pre-clinic telehealth interview and an initial one-day in-person visit involving a neurologist, neuropsychologist, geriatrician and physiotherapist. ${ }^{11}$ All patients and their families gave informed consent prior to participation. Computed tomogram imaging and blood work were included in the initial patient work-up. Patients were then seen in follow-up at 6 weeks, 12 weeks, 6 months, 12 months and annually thereafter, or more often if dictated by clinical need. Individual patients were randomly assigned to either an initial six week follow-up visit in-person in Saskatoon, or to assessment in their home community via telehealth. Subsequent follow-up visits alternated between in-person and telehealth. The first 71 patients to complete both 6 and 12 week assessments were included in the present study (Table).

Portable, high performance videoconferencing equipment was used in both locations. These set-top units are combined with a monitor to create an interactive environment. In the performance

\section{Table: Demographics and clinical characteristics of participants}

\begin{tabular}{lc}
\hline Total Number of Patients in Study & 71 \\
Age at Initial Clinic Day & \\
Mean +/- SD & 72 yrs. +/- 11 \\
Range & $42-89$ \\
Gender & $34(48 \%)$ \\
Male & $37(52 \%)$ \\
Female & \\
Initial Clinic Day - Neurologist Diagnosis & $37(52.1 \%)$ \\
Alzheimer's Disease & $11(15.5 \%)$ \\
Mild Cognitive Impairment & $9(12.7 \%)$ \\
Normal & $4(5.6 \%)$ \\
Vascular Dementia & $3(4.2 \%)$ \\
Mixed Vascular/Alzheimer's Dementia & $1(1.4 \%)$ \\
Vascular Cognitive Impairment & $1(1.4 \%)$ \\
Dementia with Lewy Bodies & $1(1.4 \%)$ \\
Parkinson's Disease & $1(1.4 \%)$ \\
Huntington's Disease & $1(1.4 \%)$ \\
Frontotemporal Dementia & $1(1.4 \%)$ \\
Normal Pressure Hydrocephalus & $1(1.4 \%)$ \\
Status Post-Hypoxic Encephalopathy &
\end{tabular}

of the consultation, two types of cameras were used: a general videoconferencing camera for the discussion portion of the clinic, and a specialized high-quality patient examination camera which allowed for a close up and detailed look at the patient or their writing or drawing. The connection was made across Community-Net, a broadband province-wide internet protocol (IP) network dedicated to health, executive government and education-based connections. The $768 \mathrm{kbps}$ baseline speed, enhanced with Quality of Service, provides priority queuing for telehealth applications. This real-time connection operates across a private IP network that has security measures in place to govern access, creating secure communication between locations. This technology provides high quality in both sound and video image, which is critical for successful clinical assessments.

To maximize consistency and reliability, the same neurologist administered the Mini-Mental State Examination (MMSE) to all patients at all visits. During telehealth assessments, the telehealth coordinator at the remote site provided the stimuli and materials for copying, writing, and reading. The coordinator also held out the paper required to test comprehension. The random assignment of patients and the alternation in mode of administration minimized the potential for bias related to patient improvement as a result of treatment or practice effect, or cognitive decline due to disease progression.

The MMSE was carried out according to the guidelines established by Folstein et al. ${ }^{12}$ During the attention and calculation portion of the exam, arithmetic was used, not spelling WORLD backwards. Two patients, due to visual impairment, could not complete certain portions of the examination. For these individuals their score was prorated to a score out of 30 .

A paired t-test was used to compare in-person to telehealth MMSE scores. As well, the methods of Bland and Altman were used, plotting the differences between in-person and telehealth against their mean, with a 95\% confidence interval for the differences. ${ }^{13}$ The method described by Bland and Altman ${ }^{13}$ is useful in determining agreement between two clinical assessments.

\section{Results}

Of the 71 subjects included in the analysis (Table), 34 were initially assessed by telehealth, and 37 in person, for a total of 142 MMSE administrations. There was no significant difference between MMSE scores when administered by telehealth $(22.70$ $+/-6.51)$ vs. in person $(22.34+/-6.35)(p=.223)$.

The agreement between the two modalities may also be presented graphically using the Bland-Altman method. ${ }^{13}$ The difference in MMSE score (in-person minus telehealth) is plotted against each subject's mean MMSE score on telehealth and inperson assessments. The mean difference (+/- SD; 95\% limits of agreement) of in-person MMSE score minus telehealth scores, was $-0.37+/-2.508(-5.386$ to 4.646$)$. The graphical presentation of these results (Figure) demonstrates that although there is a slight tendency to perform better on telehealth assessments (mean of IP-TH $=-0.37$ ), there are 30 data points below the mean and 37 above, almost all within the $95 \%$ confidence interval. Thus, no significant difference exists between testing modalities. The precision of the lower (-6.41 to -4.36 ) and the upper (3.62 to 5.67) limits of agreement for the $95 \%$ confidence interval are narrow, demonstrating a sufficiently large sample size and a 


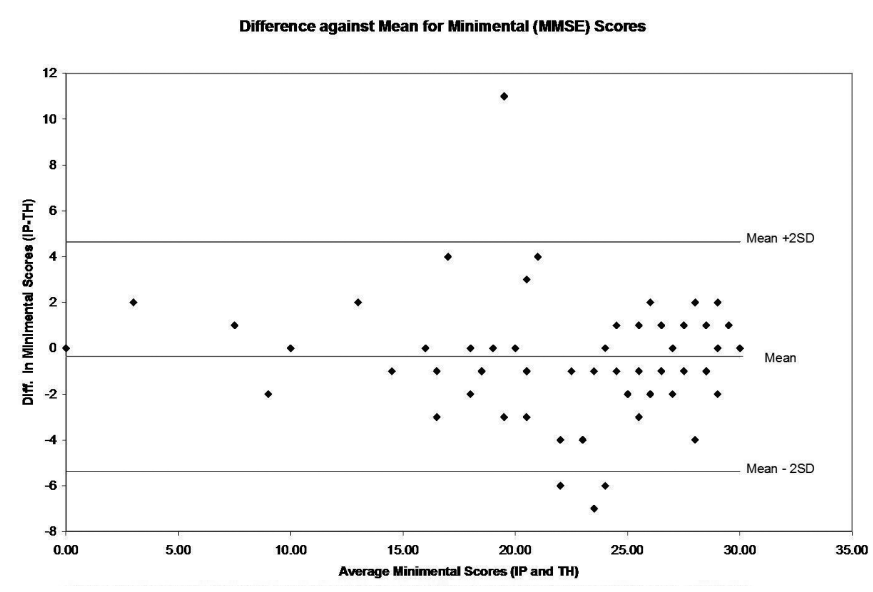

Figure: The difference in MMSE score, (in-person minus telehealth), is plotted against each subject's mean MMSE score on telehealth and inperson assessments, as per Bland and Altman..$^{13}$ Some data points represent more than one individual.

minimal variation of the differences between the two assessment methods.

\section{Interpretation}

This study demonstrates no significant difference between inperson and telehealth MMSE scores, however it must be kept in mind that the MMSE itself has poor reliability. ${ }^{14}$ Potential bias in testing could have resulted due to mode of administration, in that some patients may have preferred one modality over another. The convenience of not having to travel may have altered energy and mood, resulting in better telehealth performance. This is a consideration in the geriatric population. However, the interpersonal dynamic of having the interviewer in the same room may have resulted in better in-person MMSE scores for other individuals. As well, unfamiliarity with technology and sensory impairments may have caused others to perform more poorly during telehealth assessments. However, the Figure shows that there was generally excellent agreement between telehealth and in-person scores by individual patients.

Most studies examining telehealth and in-person administrations of the MMSE have shown high correlations, but measures of equivalency ${ }^{13}$ have been lacking.,15,16 Given that the same tool, the MMSE, was used, a correlation between telehealth and in-person assessments would be expected. To better determine the interchangeability of assessment modalities a measurement of clinical agreement was used according to the methods of Bland and Altman. Other studies have had small sample sizes, tested normal subjects, and had more than one examiner performing the testing. ${ }^{9}$ In another study of remote versus in-person assessment, the "remote" location was an adjacent room. ${ }^{6}$ Strengths of the present study are that it was conducted in a real clinical setting from a referral base, all patients had neuropsychological testing and neurologic examination at baseline, the telehealth assessments were performed with the patients in an actual rural setting, and the same neurologist administered all the MMSEs. The large sample size also helped to normalize variation.

Telemedicine services for dementia have been shown to decrease acute hospitalizations. ${ }^{17}$ Telehealth may also be useful in diagnosing dementia. ${ }^{18}$ Early diagnosis of dementia has been shown to increase treatment response ${ }^{19,20}$ and decrease health care costs. ${ }^{21}$ Therein lies the importance of a memory clinic that can reliably assess dementia patients at a distance. We conclude that telehealth is an acceptable approach to brief mental status examination for those in remote areas.

\section{ACKNOWLEDGEMENT}

Supported in part by a New Emerging Team grant from CIHR Institute of Aging, CIHR Institute of Health Services and Policy Research, CIHR Rural and Northern Health Initiative, the Saskatchewan Health Research Foundation, the Alzheimer Society of Saskatchewan, and the University of Saskatchewan. We are grateful to the Telehealth Saskatchewan Network for inkind support for facilitating this research from its earliest stages.

We acknowledge Julie Kosteniuk and Maria Ji for their assistance in managing the Memory Clinic database, and Chandima Karunanayake for her assistance with the statistical analysis.

\section{REFERENCES}

1. Jennett PA, Scott RE, Affleck Hall L, Hailey D, Ohinmaa A, Anderson C, et al. Policy implications associated with the socioeconomic and health system impact of telehealth: a case study from Canada. The experience in Alberta, Canada. Telemed J E Health, Special Canadian Issue. Spring 2004; 10(1):77-85.

2. Statistics Canada. Portrait of the Canadian population in 2006, by Age and Sex [Internet]. Ottawa, Canada: Statistics Canada; 2007 July 17 [2006 Census; [cited 2007 July 24]. Available from: http://www12.statcan.ca/english/census06/analysis/agesex/ index.cfm.

3. Sclater K, Alagiakrishnan K, Sclater A. An investigation of videoconferenced geriatric medicine grand rounds in Alberta. $\mathrm{J}$ Telemed Telecare. 2004; 10(2):104-7.

4. Poon P, Hui E, Dai D, Kwok T, Woo J. Cognitive intervention for community-dwelling older persons with memory problems: telemedicine versus face-to-face treatment. Int $\mathrm{J}$ Geriatr Psychiatry. 2005; Mar20(3):285-6.

5. McBain L, Morgan D. Telehealth, geography, and jurisdiction: issues of healthcare delivery in Northern Saskatchewan. Canadian Woman Studies. 2006; 24(4):123-9.

6. Montani C, Billaud N, Couturier P, Fluchaire I, Lemaire R, Malterre $\mathrm{C}$, et al. "Telepsychometry": a remote psychometry consultation in clinical gerontology: preliminary study. Telemed J. 1996; 2(2): 145-50.

7. Montani C, Billaud N, Tyrrell J, Fluchaire I, Malterre C, Lauvernay $\mathrm{N}$, et al. Psychological impact of a remote psychometric consultation with hospitalized elderly people. J Telemed Telecare. 1997; 3(3):140-5.

8. Ball C, Tyrrell J, Long C. Scoring written material from the minimental state examination: a comparison of face-to-face, fax and video-linked scoring. J Telemed Telecare. 1999; 5(4):253-6.

9. Loh PK, Ramesh P, Maher S, Saligari J, Flicker L, Goldswain P. Can patients with dementia be assessed at a distance? the use of telehealth and standardised assessments. Intern Med J. 2004; May 34(5):239-42.

10. Morgan D, Stewart N, Crossley M, D'Arcy C, Biem J, Kirk A, et al. Dementia care in rural and remote areas: the first year of a CIHR new emerging team. CJNR. 2005; 37(1):177-82. 
11. Morgan D, Crossley M, Kirk A, D'Arcy Stewart N, Biem J, et al. Improving access to dementia care: development and evaluation of a rural and remote memory clinic. Aging and Mental Health. [In press] March 2008.

12. Folstein MF, Folstein SE, McHugh PR. Mini-mental state: a practical method for grading the cognitive state of patients for the clinician. J Psychiatr Res. 1975; Nov12(3):189-98.

13. Bland JM, Altman DG. Statistical methods for assessing agreement between two methods of clinical measurement. Lancet. 1986; Feb 8 1(8476):307-10

14. Bowie P, Branton T, Holmes J. Should the Mini Mental State Examination be used to monitor dementia treatments? Lancet. 1999; Oct 30 354(9189):1527-8.

15. Ball CJ, Scott N, McLaren PM, Watson JP. Preliminary evaluation of a low-cost VideoConferencing (LCVC) system for remote cognitive testing of adult psychiatric patients. Br J Clin Psychol. 1993; Sept32(3):303-7.

16. Montani C, Klientovsky K, Tyrrell J, Ploton L, Couturier P, Franco A. Feasibility of psychological consultation with elderly demented patients. J Telemed Telecare. 1998; 4 Suppl 1:111.
17. Lyketsos CG, Roques C, Hovanec L, Jones BN, 3rd. Telemedicine use and the reduction of psychiatric admissions from a long-term care facility. J Geriatr Psychiatry Neurol. 2001; 14(2):76-9.

18. Shores MM, Ryan-Dykes P, Williams RM, Mamerto B, Sadak T, Pascualy $\mathbf{M}$, et al. Identifying undiagnosed dementia in residential care veterans: comparing telemedicine to in-person clinical examination. Int J Geriatr Psychiatry. 2004; Feb 19(2): 101-8.

19. Raskind MA, Peskind ER, Wessel T, Yuan W. Galantamine in AD: a six-month randomized, placebo-controlled trial with a sixmonth extension. the galantamine USA-1 study group. Neurology. 2000; Jun 27 54(12):2261-8.

20. Doody RS, Geldmacher DS, Gordon B, Perdomo CA, Pratt RD, Donepezil Study G. Open-label, multicenter, phase 3 extension study of the safety and efficacy of donepezil in patients with alzheimer disease. Arch Neurol. 2001; Mar 58(3):427-33.

21. Lawrence J, Davidoff D, Katt-Lloyd D, Auerbach M, Hennen J. A pilot program of improved methods for community-based screening for dementia. Am J Geriatr Psychiatry. 2001; 9(3): $205-11$. 